\title{
O PROFEPT COMO ESPAÇO DE REFLEXÃO E FORMAÇÃO DOCENTE SUPERIOR NA EDUCAÇÃO PROFISSIONAL E TECNOLÓGICA
}

\author{
Elen de Fátima Lago Barros Costa*, Maria Cristina Santos \\ *E-mail: relen@ifma.edu.br \\ Instituto Federal de Educação, Ciência e Tecnologia do Maranhão \\ DOI: $10.15628 /$ rbept.2020.11151 \\ Artigo submetido em: set/2020 e aceito em: nov/2020
}

\begin{abstract}
RESUMO
A Educação Profissional e Tecnológica (EPT), tem como princípio a formação humana integral e para o mundo do trabalho. Para atuar no ensino na EPT é imprescindível uma formação docente sólida que permita aos professores compreender a relação intrínseca entre educação e trabalho. Neste artigo analisaremos o Programa de Pós-graduação em Educação Profissional e Tecnológica/PROFEPT, afirmando a sua importância como um espaço acadêmico para a reflexão e formação de docentes que atuam nesta modalidade de ensino. Para a compreensão do objeto de estudo e suas categorias, define-se como método de abordagem o materialismo histórico dialético. No que diz respeito aos procedimentos metodológicos trata-se de revisão de literatura e pesquisa documental. Espera-se com este artigo contribuir para o debate sobre a importância de adotar uma política de formação docente condizente com os desafios enfrentados, na atual conjuntura econômica.
\end{abstract}

Palavras-chaves: Trabalho e Educação. Formação Docente na EPT. PROFEPT.

\section{THE PROFEPT GRADUATE PROGRAMME AS A SPACE FOR CRITICAL THOUGHT AND TEACHERS' QUALIFICATION AT THE PROFESSIONAL AND TECHNOLOGY EDUCATION}

\begin{abstract}
One of the tenets for the Professional and Technology Education (PTE) is the preparation for work. In order to work on PTE teaching it is essential to obtain an appropriate qualification that allow teachers to understand the relations between labor and education. Thus, the aim of this paper is analyse the Professional and Technologic Education Graduate Programme, reinforcing its level of importance as an academic space for critical thought and teacher training targeted to those who work on this teaching modality. In order to comprehend the research object of this study and its categories, the historical and dialectical materialism methods has been defined to carry out the research. With regard to methodological procedures, it is a literature review and documentary research. This article is expected to contribute to the debate on the importance of adopting a teacher training policy consistent with the challenges faced, in the current economic situation.
\end{abstract}

Keywords: Labour and Education; Teacher qualification at PTE; PROFEPT. 


\section{INTRODUÇÃO}

Numa sociedade de classes compreender as políticas educacionais requer o reconhecimento de que nesta sociedade coexistem tipos diferenciados de ensino/escola e, portanto, estas políticas refletem essa dualidade. $\mathrm{O}$ grande erro de algumas análises sobre a educação num país capitalista é o de "tratá-la em si mesma e não como constituída e constituinte de um projeto dentro de uma sociedade cindida em classes, frações de classes e grupos sociais desiguais" (FRIGOTTO, 2007, p. 1113).

Olhando para a realidade histórica de forma dialética compreendemos que a educação escolar, embora tenha como função a reprodução das relações sociais capitalistas, por se darem numa sociedade de classes, se produz dentro de contradições, conflitos, antagonismos e disputas. Assim, mesmo que ela tenha essa função, não se reduz a ela, pois tanto a educação em geral que se dá nas relações sociais quanto os processos educativos e os conhecimentos específicos produzidos e disseminados pela escola de educação básica e nos processos de qualificação técnica e tecnológica interessam a classe trabalhadora e a seu projeto histórico de superação do modo de produção capitalista (FRIGOTTO, 2006, p. 241)

Apesar dos avanços, fruto dos embates da sociedade civil organizada e da implementação de políticas governamentais mais "progressistas"1, ainda persiste na educação do país a diferenciação na oferta de ensino de acordo com as camadas sociais, uma para a elite e outra para a classe trabalhadora, permanecendo, ainda hoje, a a distinção que Gramsci (1991, p. 118) encontrou, a décadas atrás, uma escola profissional destinada às classes instrumentais, ao passo que a clássica destina-se às classes dominantes e aos intelectuais. Do ensino fundamental ao ensino superior este sistema educacional dual é organizado e implementado de tal maneira que a existência destas escolas desiguais traz desdobramentos que vão desde os conteúdos curriculares diferenciados à formação dos professores que atuarão nestes espaços.

No que diz respeito aos conteúdos curriculares percebe-se que estes sempre estiveram articulados às exigências formativas de cada época e o currículo escolar, historicamente, esteve a serviço das necessidades de reprodução do sistema econômico. No atual estágio de acumulação do capital e das novas tecnologias, por exemplo, exige-se da escola que cumpra o papel de espaço da formação flexível e polivalente, em que ao indivíduo é requerido um conjunto de competências e habilidades que extrapolam uma mera formação técnica específica. Apesar de reconhecermos que no Brasil, nem sempre, a escola ofertada para a classe trabalhadora cumpre com essa

\footnotetext{
1 Se comparadas as políticas anteriores, percebe-se que os períodos dos dois mandatos do Governo Luiz Inácio Lula da Silva (2003-2010), assim como de sua sucessora Dilma Rousseff (2011 a 2014 e 2015 a dias atuais), são emblemáticos no que concerne ao contexto político-econômico, ao paradigma educacional assumido e às reformas decorrentes deste novo modelo e, consequentemente, das mudanças nas instituições republicanas, espaços legitimadores em que se materializam estas políticas. (COSTA, 2016)
} 
formação visto que ainda se encontram escolas que formam nos moldes taylorista-fordista, no discurso oficial, a formação humana está explicitamente relacionada a capacidade que o homem tem para acompanhar as rápidas transformações do modo de produção. Como afirma Moura (2014, p. 14), cabe a escola capitalista, "fortalecer o modo de produção do capital que se baseia na valorização diferenciada do trabalho intelectual e do trabalho manual".

Tal como a sociedade dividida em classes a escola permanece cindida e perpetua esse sistema em detrimento de uma escola que promova a formação do indivíduo nas dimensões intelectual, cultural e humanística. A escola que temos oferece um ensino baseado no "adestramento em uma determinada habilidade sem o conhecimento dos fundamentos dessa habilidade e, menos ainda, da articulação dessa habilidade com o conjunto do processo produtivo"(SAVIANI, 2007, p. 161), ou seja, a lógica do capital imprimiu mudanças significativas, impondo o paradigma do atual padrão produtivo para a organização escolar, assim como retirando, em grande parte, a autonomia do docente, que, cada vez mais, se vê subsumido ao capital.

Neste contexto, que analisamos o trabalho e a formação docente, compreendendo que em todos os momentos históricos que existiu essa profissão, ela reflete uma forma específica de organização do trabalho e requer análises para além dos aspectos pedagógicos compreendendo o lugar social ocupado pelos profissionais da educação.

Diante destas reflexões iniciais explicita-se que este artigo adota como referencial teórico metodológico o materialismo histórico dialético e quanto as técnicas de pesquisa trata-se de uma pesquisa bibliográfica e documental em que foram analisados documentos referentes ao PROFEPT, assim como, realizou-se um estudo sistemático acerca das reflexões de autores de base marxiana - Demerval Saviani, Gaudêncio Frigotto, Acácia Kuenzer, Maria Ciavatta, Dante Moura, Marise Ramos, dentre outros - que tem como objeto de estudo a defesa do ensino na EPT tendo como princípios a relação educação e trabalho, a formação ominilateral e politécnica e o trabalho como princípio educativo.

\section{FORMAÇÃO DOCENTE NA EDUCAÇÃO PROFISSIONAL E TECNOLÓGICA: PRINCÍPIOS NORTEADORES E DESAFIOS NA ATUALIDADE}

Existem inúmeras formas explicativas e propositivas de formação de professores no geral e para a EPT, em específico. Cabe salientar que nos colocamos ao lado daqueles que defendem a importância da escola para a formação da classe trabalhadora, o fortalecimento da escola e que esta deve privilegiar a organização intencional dos conteúdos considerando as condições objetivas para sua efetivação. Acreditamos na objetividade da realidade concreta e que essa realidade é cognoscível, portanto, nos opomos 
a teorias do aprender a aprender e do professor reflexivo, centradas na sala de aula, na sua maneira de ensinar, na experiência pessoal.

O saber da experiência é relevante no processo de constituição do sujeito, evidentemente, porém, não deve substituir nem ocupar o lugar da formação teórica, metodológica, didática e técnica.

A formação do professor, como a de qualquer outro trabalhador ou categoria profissional deve se dar sobre uma sólida base teórica, intencionalmente planejada e dirigida que não busque apenas a instrução e adaptação, mas que possibilite ao sujeito se compreender como tal, e, os esforços para sua auto transformação seja indissociável dos esforços para a transformação social.

Quando paramos para analisar o que seria ideal na formação do professor no âmbito da EPT e o necessário para a formação do trabalhador, nos deparamos com um consenso nos debates/estudos progressistas de que esta modalidade, quer seja nas suas articulações com o Ensino Médio ou como curso profissionalizante, deve ter como pressuposto a relação intrínseca entre trabalho e educação, pautados nos princípios da politecnia, da formação omnilateral, do trabalho como princípio educativo e da qualificação para o mundo do trabalho. São estas bases que devem ou deveriam alicerçar a formação inicial e continuada dos professores que atuam nesta modalidade. No momento em que o pragmatismo empirista predomina na formação da classe trabalhadora, cabe a nós, recuperar a relação entre conhecimento e a prática do trabalho. (SAVIANI, 2007).

A formação e a atuação exigida para estes profissionais seria atuar tendo como pressuposto um conjunto diferenciado de exigências que envolvem vários fatores: apropriação da cultura científica e teórico-técnica de sua área de formação, capacidade para atuar utilizando a tecnologia, o entendimento das especificidades da EPT e a compreensão do seu papel de formar a classe a qual ele mesmo pertence, ou seja, o compromisso éticopolítico relacionado ao sentimento de pertencimento a classe trabalhadora.

Além disso, não basta o domínio técnico e a qualificação profissional, é imprescindível o domínio de metodologias de ensino adequadas para a transmissão do saber no processo ensino-aprendizagem que é uma ação entre sujeitos, com funções diferentes: envolve o sujeito do ensino, o professor, em relação com o sujeito da aprendizagem, o aluno. Quanto ao conhecimento específico , o profissional deve atuar com competência e domínio dos conteúdos de sua área de formação e, para tanto, além da formação inicial adquirida nos cursos de graduação, cabe ao docente estar em permanente processo de atualização para acompanhar as constantes transformações impostas pela sociedade em movimento e mais que isso, que atue na perspectiva da formação integral das novas gerações e não somente para o mercado de trabalho.

Entretanto, as estatísticas nacionais apontam para o fato de que muito dos profissionais que atuam na EPT são bacharéis sem a devida e necessária formação pedagógica e/ou licenciados que não apresentam formação didático-pedagógica para atuar nas especificidades da EPT e, 
somado a isso muitos não despertaram para o fato de que esta modalidade traz em sua efetivação aspectos ideológicos que merecem atenção e cautela. Além da competência técnica, exige-se compromisso político no sentido do domínio dos conhecimentos próprios de sua área específica, mas, também, habilidade para organizar e transmitir esse conhecimento da melhor maneira possível, de modo que os alunos assimilem o conteúdo ensinado. Saber sobre o que há de mais relevante sobre a prática pedagógica, ter entendimento sobre a organização e funcionamento da escola, agrupamentos de alunos, dos períodos, currículo método de ensino (SAVIANI, 2000).

A escola capitalista não explicita claramente o ideário da classe dominante e a intencionalidade que esta classe tem para com a formação da classe trabalhadora e, o ato político consiste em compreender de que modo isso se manifesta, por vezes escamoteado por reformas educacionais, esvaziamento do papel da escola e do conteúdo escolar, esvaziamento e esfacelamento do trabalho do professor, intensificação e precarização das relações de trabalho e de ensino, ênfase para processos e técnicas em detrimento do conteúdo do ensino. Com isso é possível captar as técnicas de exclusão e eliminação dos alunos provenientes das classes trabalhadoras pela escola capitalista. Referente a capacidade para atuar utilizando os avanços tecnológicos, esta habilidade diz respeito ao uso dos objetos técnicos e dos fatos tecnológicos. Segundo Machado (2008, p. 15),

\begin{abstract}
Os professores da educação profissional enfrentam novos desafios relacionados às mudanças organizacionais que afetam as relações profissionais, aos efeitos das inovações tecnológicas sobre as atividades de trabalho e culturas profissionais, ao novo papel que os sistemas simbólicos desempenham na estruturação do mundo do trabalho, ao aumento das exigências de qualidade na produção e nos serviços, à exigência de maior atenção à justiça social, às questões éticas e de sustentabilidade ambiental. São novas demandas à construção e reestruturação dos saberes e conhecimentos fundamentais à análise, reflexão e intervenções críticas e criativas na atividade de trabalho.
\end{abstract}

Nesta perspectiva, espera-se da docência na EPT a compreensão da realidade social e que viabilizem aos alunos os conhecimentos técnicos necessários, mas acima de tudo uma visão crítica sobre as questões/relações intrínsecas ao modo de produção capitalista. E nesta direção analisa Oliveira (2000, p. 42),

[...] a formação dos alunos nas escolas de EPT não se resumiria a uma formação voltada apenas para o domínio das técnicas de execução de atividades e tarefas no setor produtivo e de serviços, mas [...] envolveria, entre outros, o compromisso com o domínio, por parte do trabalhador, dos processos físicos e organizacionais ligados aos arranjos materiais e sociais e do conhecimento aplicado e aplicável, pelo domínio dos princípios científicos e tecnológicos próprios a um determinado ramo de atividade humana.

No que diz respeito a compreensão das especificidades da EPT - a relação intrínseca entre educação e trabalho, a educação politécnica, a formação omnilateral, o trabalho como princípio educativo e a formação para 
o trabalho - compreendemos que não são princípios desenvolvidos na formação inicial docente, entretanto, não podemos pensar uma EPT que não seja baseada nestes fundamentos até por que a própria atuação exigirá o domínio profissional deste espaço. É imprescindível que haja uma formação continuada robusta/consistente, condição para se conhecer a escola tal qual ela é e no seu vir a ser.

Segundo Machado (2008, p. 21),

[...] é fundamental que conste da formação pedagógica dos docentes da educação profissional conteúdos sobre a educação brasileira, a história da educação profissional, as relações da educação profissional com o contexto econômico-social, os fundamentos da relação entre trabalho e educação, a discussão sobre produção de saberes no e sobre o trabalho, os espaços de articulação entre escola e trabalho, a influência das redes de pertencimento como legitimação e valorização dos sujeitos e seus saberes, mudanças no mundo do trabalho e suas implicações para a educação, políticas e legislação da educação profissional, objetivos e especificidades da educação profissional, conceitos e paradigmas sobre currículo na educação profissional, relações entre currículo, educação, cultura, tecnologia e sociedade; dualidade na organização curricular e currículo integrado; a construção curricular na educação profissional, didática e educação profissional, organização e planejamento da prática pedagógica na educação profissional, avaliação do processo de ensinoaprendizagem na educação profissional, docência na educação profissional etc.

É preciso que esses profissionais conheçam o discurso oficial da EPT e, principalmente, compreendam as nuances ideológicas que estão para além do fenômeno aparente desse discurso. Reconhecer que vivenciamos uma reestruturação do processo produtivo, que a escola capitalista tem uma intencionalidade que não se explicita claramente, mas que, por meio de discursos que defendem a importância de diplomas de ensino técnico e tecnológico em detrimento de diplomas de ensino superior atuará para garantir a formação de indivíduos aptos a atuarem nesta sociedade mas que ao educador cabe desvelar, através da sua pratica consciente e crítica, esta visão utilitarista e dual do ensino e trabalhe em busca de uma formação humana que vá ao encontro dos anseios do indivíduo, que os faça compreender o processo produtivo e saiba atuar nele com discernimento e como sujeito. O estado, como aparelho ideológico e repressivo a serviço da classe dominante, está, portanto, posicionado na luta de classes e como tal, age de forma a preservar os privilégios dessa classe, na ampliação e manutenção da acumulação capitalista (ALTHUSSER, 1985). Dessa forma, a educação escolar que propiciará à classe trabalhadora será uma manifestação desses interesses de reprodução do capital e não necessariamente de formação ampla e acesso ao conhecimento historicamente sistematizado.

Como afirma Shiroma (2012, p. 31), este mesmo Estado é também constituído por, 
atores sociais que defendem o interesse na manutenção de um tipo de ensino aligeirado e produtor de efetivos renováveis, destinado a ocupar postos de trabalhos de baixa remuneração porque, ao lado da qualificação, contraditoriamente, o modo capitalista de produção necessita produzir um exército de reserva.

Quanto ao compromisso ético-político e sentimento de pertencimento a classe trabalhadora, apesar do reconhecimento que este sentimento de identidade está relacionado às vivências pessoais ou práticas sociais do indivíduo, consideramos que esta formação política pode ser realizada nas instituições escolares, ou seja, na formação inicial e continuada descrita nos parágrafos anteriores. Nesse sentido, afirma Moura (2014, p. 33),

[...] é fundamental para o professor compreender-se nessa
condição, ou seja, enquanto pertencente à classe trabalhadora,
quer seja na educação básica, na educação superior, na educação
profissional, enfim em qualquer nível, etapa ou modalidade
educacional. Essa consciência de classe vai contribuir,
sobremaneira, para que o professor assuma o compromisso ético-
político com um projeto de sociedade da classe trabalhadora e,
portanto, com um projeto de formação humana emancipada,
integral, omnilateral.

Neste sentido, o trabalho educativo, em qualquer nível, requer um conjunto de exigências, mas em se tratando da educação profissional e tecnológica, há uma complexidade maior, uma vez que, mais que o trabalho puramente acadêmico, acentua a exigência de formadores com domínio de conteúdos e técnicas laborais e de metodologias de aprendizagem que estejam sintonizados com a realidade concreta.

Este perfil de formação requer o conhecimento, apropriação das tecnologias, desenvolvimento nacional, local e regional sustentável e incita os sujeitos da educação profissional para que se coloquem verdadeiramente como sujeitos da reflexão e da pesquisa, abertos ao trabalho coletivo e à ação crítica cooperativa, o que se traduz como um lidar reflexivo que realmente trabalhe a tecnociência. (COSTA, 2016)

\section{O PROFEPT E A FORMAÇÃO DOCENTE PARA A EDUCAÇÃO PROFISSIONAL E TECNOLÓGICA}

A política nacional de formação docente para a EPT deve ser pensada por toda a sociedade civil, mas é de responsabilidade do Estado, como órgão arrecadador dos impostos e eixo central do financiamento das políticas públicas de educação, definir, legislar e acompanhar, no âmbito da esfera pública e privada, a oferta da formação dos profissionais da educação que atuam nesta modalidade de ensino.

Entretanto, o que se vê é um estado, que por ser de classe, atua na perpetuação das relações sociais capitalistas e na ampliação dos lucros do capital e isso, evidentemente, reverbera nas elaborações políticas voltadas a 
formação do trabalho, no caso, do trabalhador. Segundo Machado (2008, p. 11) "a falta de concepções teóricas consistentes e de políticas públicas amplas e contínuas tem caracterizado, historicamente, as iniciativas de formação de docentes especificamente para a educação profissional, no Brasil". Analisando a legislação educacional, em particular a Lei 9.394/1996 (BRASIL, 2017), percebe-se uma lacuna quanto a formação docente específica para a atuação na EPT e as implicações da ausência desta formação no trabalho do professor é percebida quando analisamos as práticas pedagógicas desenvolvida nas salas de aulas de cursos profissionalizantes.

A referida lei, portanto, trata da formação generalista para a educação básica e no ensino superior, o que com certeza não contempla as especificidades da EPT. No artigo 62, preconiza que, a "formação de docentes para atuar na educação básica far-se-á em nível superior, em curso de licenciatura plena, admitida, como formação mínima para o exercício do magistério na educação infantil e nos cinco primeiros anos do ensino fundamental, a oferecida em nível médio, na modalidade normal". (BRASIL, 2017, p. 42).

Atualmente a formação docente é tratada de maneira genérica tendo como pressuposto a Base Nacional Comum Curricular/BNCC e atendendo às especificidades do exercício de suas atividades, bem como aos objetivos das diferentes etapas e modalidades da educação básica tendo como fundamentos "I - a presença de sólida formação básica, que propicie o conhecimento dos fundamentos científicos e sociais de suas competências de trabalho; II - a associação entre teorias e práticas, mediante estágios supervisionados e capacitação em serviço." (BRASIL, 2017, p. 42)

Percebe-se neste excerto que a lei preconiza uma formação básica sólida e capacitação em serviço como estratégias para essa qualificação docente, cabe as instituições formadoras contemplar conteúdos e espaços voltados para as especificidades de cada nível ou modalidade de ensino, portanto, a formação inicial e continuada ficaria a cargo das instituições superiores e/ou técnicas. Mas infelizmente no âmbito da formação inicial destacam-se poucos cursos de graduação ${ }^{2}$ para esse tipo de formação oferecidos por algumas instituições superiores privadas.

Quanto a formação continuada, seguindo o artigo 66 da LDB (BRASIL, 2017, p. 44), que define que "a preparação para o exercício do magistério superior far-se-á em nível de pós-graduação, prioritariamente em programas de mestrado e doutorado" conseguimos identificar algumas iniciativas públicas e privadas ${ }^{3}$.

2 Um exemplo interessante de curso de formação inicial/graduação específicos para a EPT e ofertado pela rede pública o Curso de Pedagogia e Educação Profissional e Tecnológica, em rede, ofertada por 07 Institutos Federais.

\section{3} pública destaca-se: o Curso em Formação Pedagógica para Docência na Educação Profissional/IFMA; Gestão Pública na Educação Profissional e Tecnológica/IFSC; Políticas e Gestão da Educação Profissional e Tecnológica/IFGO, dentre outros. 
Devido as mudanças no processo de produção e no incremento da tecnologia ocorrida no Brasil nos anos 90 do século $X X$ e consolidadas no século XXI, o Governo Federal, para atender as necessidades do novo paradigma produtivo expandiu a oferta da EPT e criou uma nova rede formada pela fusão das instituições já existentes no país ${ }^{4}$. Neste sentido, surge uma nova institucionalidade com a criação da Rede Federal de Educação Profissional, Científica e Tecnológica/RFEPCT, através da Lei 11.892/2008 (BRASIL, 2008) e, como fruto desta expansão, a necessidade de ofertar um programa que contemplassem a formação dos profissionais que atuavam e os que iriam atuar nesta modalidade de ensino.

\begin{abstract}
Nesse contexto, a RFEPCT e os IFs, alicerçados na indissociabilidade entre ensino, pesquisa e extensão, contribuem na formação de mão de obra qualificada e na proposição, elaboração e aplicação de práticas, técnicas e produtos em parceria com os setores produtivos, sociais e culturais. No tocante aos IFs, esses se constituem em importantes indutores de desenvolvimento local, regional e nacional, uma vez que são instituições habilitadas para a oferta de formação profissional e tecnológica, de pesquisa aplicada, da extensão, da produção cultural, do empreendedorismo e do desenvolvimento científico e tecnológico. (BRASIL, 2020)
\end{abstract}

Diante desta expansão, a Secretaria de Educação Profissional e Tecnológica do Ministério da Educação (SETEC/MEC) desenvolveu Diretrizes para fomentar as iniciativas da Pós-graduação em Associação ou em Rede. E nesta direção foi desenvolvido um estudo para mapear os profissionais que já atuavam na RFPCT e que não possuíam formação stricto sensu e foi constatado que, em 2014, a referida rede,

[...] possuía 25.152 docentes e desses apenas 19,4\% possuíam o título de Doutor -4.877 professores - e $48,2 \%$ possuíam o título de Mestre - 12.124 docentes, em todas as modalidades de jornada de trabalho. No mesmo ano, 8.151 docentes não possuíam qualquer título de pós-graduação stricto sensu [...] Além dos docentes, o estudo destaca, ainda em relação aos dados de 2014, que a RFEPCT possuía 22.500 servidores técnico-administrativos. As informações sobre escolaridade destes servidores mostram que $59,5 \%$ possuem um curso de nível superior; 2,8\% obtiveram Mestrado; e 0,2\% obteve o grau de Doutorado [...] ressalta-se que durante os anos recentes a acentuada expansão da RFPECT, acarretou em 56,7\% (17.507 indivíduos) do pessoal docente com menos de 5 anos em exercício.

Constatou-se, também, que os docentes da rede têm perfis muito diferenciados desde com aqueles com alta qualificação acadêmica mas pouca experiência junto ao setor produtivo, alguns com essa expertise mas sem a titulação acadêmica adequada até aqueles que não tinham formação pedagógica como também docentes que não foram capacitados para

\footnotetext{
${ }^{4}$ Desde 29 de dezembro de 2008, 31 Centros Federais de Educação Tecnológica (CEFETs), 75 Unidades Descentralizadas de Ensino (Uneds), 39 Escolas Agrotécnicas, 7 Escolas Técnicas Federais e 8 Escolas vinculadas a Universidades deixaram de existir para formar os Institutos Federais de Educação, Ciência e Tecnologia. De acordo com a Plataforma Nilo Peçanha (2019) no Brasil existem: 647 unidades, 11.766 cursos e 964.593 matrículas.
} 
promover a integração do ensino com as expectativas profissionais, sociais e econômicas do público alvo que atende e da região em que atua. (BRASIL, 2020)

Foi nesse contexto que a SETEC/MEC fomentou o incentivo a programas de pós-graduação em rede e, dentre estas iniciativas, destaca-se o Programa de Pós-Graduação em Educação Profissional e Tecnológica/ PROFEPT $^{5}$ como um programa de excelência que proporciona a formação nos princípios que defendemos neste artigo e abordamos na seção anterior. Desta forma,

Ante o exposto, o Conselho Nacional das Instituições da Rede Federal de Educação, Científica e Tecnológica (CONIF), com o apoio da SETEC/MEC, incentivou a proposição do Mestrado Profissional em Educação Profissional em Rede Nacional (ProfEPT), em função da necessidade de aperfeiçoar as práticas educativas e a gestão escolar vinculadas à EPT, em articulação com a demanda por qualificação de profissionais da rede, mas também abrindo possibilidades de formação qualificada ao público em geral, aproveitando a grande capilaridade de atuação territorial da RFEPCT para otimizar a oferta das vagas do Programa. (BRASIL, 2020, p. 1)

O PROFEPT foi criado através da Resolução 161/2016 (BRASIL, 2016) e tem como objetivo "proporcionar formação em educação profissional e tecnológica, visando tanto a produção de conhecimentos como o desenvolvimento de produtos, por meio da realização de pesquisas que integrem os saberes inerentes ao mundo do trabalho e ao conhecimento sistematizado" (BRASIL, 2018, p. 2).

Percebe-se o sucesso do programa a cada ano expresso na procura pelo mestrado através do Exame Nacional de Acesso/ENA ${ }^{6}$, que de 2017 a 2020 recebeu aproximadamente 122.751 inscritos para o processo seletivo demonstrando que o programa vem atraindo o interesse da sociedade civil que almeja ter uma formação mais adequada para atuar na EPT.

Quanto a adesão das Instituições Associadas/IA's ao programa tem sido gradativa, de acordo com as necessidades locais, a disponibilidade e capacidade de gestão institucional, conforme explicitado no artigo $8^{\circ}$,

São requisitos gerais aplicáveis às Instituições interessadas: I Assegurar o caráter inteiramente gratuito do Programa na instituição; II - Proporcionar corpo docente com pelo menos 8 (oito) docentes permanentes, com dedicação mínima de 15 horas ao programa, com título de doutor e experiência compatível ao objetivo do Programa, lotados em uma das instituições previstas no Art. 30

5 O ProfEPT é um programa de pós-graduação com um curso de mestrado profissional em Educação Profissional e Tecnológica ofertado em rede nacional, pertencente à área de Ensino e reconhecido pela Coordenação de Aperfeiçoamento de Pessoal de Nível Superior CAPES do Ministério da Educação. (BRASIL, 2018).

${ }^{6}$ Anualmente são ofertadas 24 vagas, sendo 12 para profissionais que compõem o quadro funcional da RFEPCT e 12 vagas para ampla concorrência (público externo a instituição). 
desse regulamento, sendo mais de $50 \%$ deles vinculados à Instituição Proponente e com qualificação acadêmica e técnica, prevista no Edital, que permitam assegurar a regularidade e a qualidade das atividades de ensino, pesquisa, extensão e de orientação; III - Apresentar infraestrutura física adequada e indicada no Edital para o desenvolvimento das atividades previstas no Programa; IV - Dispor de acesso a equipamentos de informática atualizados, a rede mundial de computadores e a fontes de informação multimídia para os docentes e discentes; V - Apresentar resultado do Índice Geral de Cursos (IGC-MEC) maior ou igual a 3, quando for o caso; VI - Comprometer-se com o correto cumprimento dos regulamentos, regimentos e instruções nacionais com vistas a constituir a unidade da rede. (BRASIL, 2020, p. 2)

Neste sentido, quanto a abrangência, no ano de 2019, o programa já matriculou cerca de 912 profissionais distribuídos em 38 IA's e sob a responsabilidade de aproximadamente 456 docentes. (Tabela 1)

Tabela 1: Demonstrativo da abrangência do PROFEPT/20197

\begin{tabular}{l|c|c|c}
\hline \multicolumn{1}{|c|}{ Regiões } & $\begin{array}{c}\text { Instituições } \\
\text { Associadas }\end{array}$ & $\begin{array}{c}\text { Número de } \\
\text { Docentes }\end{array}$ & $\begin{array}{c}\text { Número de } \\
\text { alunos } \\
\text { matriculados* }\end{array}$ \\
\hline Centro-Oeste & 04 & 48 & 96 \\
\hline Nordeste & 11 & 132 & 264 \\
\hline Norte & 07 & 84 & 168 \\
\hline Sudeste & 10 & 120 & 240 \\
\hline Sul & 06 & 72 & 144 \\
\hline Total & $\mathbf{3 8}$ & $\mathbf{4 5 6}$ & $\mathbf{9 1 2}$ \\
\hline
\end{tabular}

Fonte: Brasil (2020). *Aproximadamente.

O programa tem como área de concentração a Educação Profissional e Tecnológica que compreende a EPT desenvolvida em espaços formais e não formais articulados ao mundo do trabalho e à produção de conhecimento, numa perspectiva interdisciplinar, com vistas a integração dos campos do Trabalho, da Ciência, da Cultura e da Tecnologia, assim como, reflete sobre os espaços educativos em suas dimensões de organização e implementação, com um enfoque de atuação que objetiva promover a mobilização e a articulação de todas as condições materiais e humanas necessárias para garantir a formação integral do estudante (BRASIL, 2018).

\footnotetext{
7 O quantitativo de alunos matriculados e docentes são dados aproximados considerando informações coletadas no site do programa em que cada IA deverá ter 12 docentes e 24 discentes por ENA.
} 
Esta área de concentração comporta duas linhas de pesquisa Práticas Educativas em EPT $^{8}$ e Organização e Memórias de Espaços Pedagógicos na Educação Profissional e Tecnológica ${ }^{9}$. Essas linhas se articulam na perspectiva de propiciar uma formação que atenda as necessidades requeridas para a EPT.

Este programa tem como referencial teórico-metodológico o materialismo histórico dialético e tem como bases conceituais a busca pela articulação entre trabalho e educação, defendendo para os espaços formativos da EPT, tanto para os docentes que nela atuam como para os discentes que são a clientela desta modalidade, a formação humana omnilateral/integral, a educação politécnica e o trabalho como princípio educativo.

O entendimento da formação humana omnilateral/integral e educação politécnica está baseada nos princípios de escola unitária de Gramsci ao defender que a formação do trabalhador deve partir de uma concepção de "escola desinteressada" visando a sua emancipação. Essa escola representaria "um novo desenvolvimento do conceito socialista de educação e marca uma ruptura dialética com a ideia de 'instrução geral e politécnica' ou de 'escola única do trabalho', desenvolvida no contexto soviético". (DORE, 2006, p. 342)

O programa ao defender a articulação entre trabalho e educação propõe a superação do princípio educativo clássico que se baseia na formação profissionalizante meramente técnica e instrumental. $E$ nesta perspectiva reafirma a defesa que o ensino médio e a educação profissional estejam pautados na formação politécnica tendo como princípio educativo o trabalho. Convém ressaltar que a defesa destes princípios são a base da educação socialista defendida pelos clássicos do marxismo que segundo Machado (2020, p. 25), a defesa desses princípios pedagógicos esteve marcado por uma "profunda preocupação ética com relação ao significado do trabalho na sociedade socialista, ao respeito pelo trabalhador, ao

8 Trata dos fundamentos das práticas educativas e do desenvolvimento curricular na Educação Profissional e Tecnológica, em suas diversas formas de oferta, com foco nas estratégias transversais e interdisciplinares, que possibilitem formação integral e significativa do estudante, sustentados no trabalho como princípio educativo e na pesquisa como princípio pedagógico, em espaços formais e não formais. Considera, também, às questões relacionadas à Educação de Jovens e Adultos, à Educação Indígena, à Educação e Relações Étnico-raciais, à Educação Quilombola, à Educação do Campo, às Questões de Gênero e à Educação para Pessoas com Deficiências (PCDs) e sua relação com as diversas práticas do mundo do trabalho. (BRASIL, 2018)

9 Trata dos processos de concepção e organização do espaço pedagógico na Educação Profissional e Tecnológica, com foco nas estratégias transversais e interdisciplinares, que possibilitem formação integral e significativa do estudante, sustentados no trabalho como princípio educativo e na pesquisa como princípio pedagógico, em espaços formais e não formais. Considera, também, a construção temporal, através dos estudos de memória da Educação Profissional e Tecnológica, que ao longo do tempo, vem configurando os processos de ensino e de organização de seus espaços pedagógicos. (BRASIL, 2018) 
desenvolvimento de atitudes morais para com o trabalho e ao caráter humanista e coletivista do trabalho socialista".

A defesa ontológica do trabalho como princípio educativo sustenta a ideia de que o homem se desenvolve individualmente e coletivamente pelo trabalho. Portanto, é a partir do trabalho que ele se humaniza e, nesta perspectiva, o trabalho precisa ser o pressuposto para o processo formal/ informal do ato de educar.

[...] para Gramsci, o processo de trabalho como princípio educativo é imprescindível na formação de novos intelectuais orgânicos para a classe trabalhadora que, organizada, concretize o ideal de uma sociedade emancipadora, onde tanto o trabalho material quanto o trabalho imaterial absorva uma visão crítica da realidade, uma visão coerente e unitária, que leve em conta a racionalidade, a totalidade e a historicidade das relações sociais. (MACHADO, 2008, p. 289)

Defender estes princípios e fundamentos no PROFEPT é proporcionar dois eixos de atuação: a) enquanto formação docente de nível superior viabilizar um local para o debate crítico das questões inerentes a educação brasileira e em particular a práxis pedagógica na EPT; b) enquanto espaço de resistência, proporcionar uma formação sólida e consistente para a classe trabalhadora, ampliando sua inserção social a medida que os profissionais formados no programa disseminem esses conhecimentos em seus espaços de trabalho. Ou seja, o programa não se constitui em apenas uma formação acadêmica em nível stricto sensu, mas, principalmente, representa a defesa de um tipo de formação que almejamos para a "classeque-vive-do-trabalho". (ANTUNES, 2007)

Constitui-se, portanto, num espaço formativo que prima pelas bases e fundamentos da EPT visando formar profissionais que atuem nas salas de aula tendo como foco a superação da dicotomia entre ambiente acadêmico/ escolar e o setor produtivo. Mais do que um mestrado profissional o programa defende ideias/ideais que coadunam com uma perspectiva de educação revolucionária e contra hegemônica voltada a classe trabalhadora.

Considera-se que desenvolver esta perspectiva de ensino é uma tarefa revolucionária na medida em que, mesmo compreendendo o caráter de exploração hegemônico da sociedade capitalista e que para realização dessa hegemonia a classe dominante utiliza suas instituições para a manutenção da ordem vigente, coexiste um espaço da contradição que podemos atuar. Como afirma Dore $(2006$, p. 338$)$, numa perspectiva gramsciana "se o surgimento da sociedade civil mostra o intenso trabalho educativo da classe dominante para garantir o consenso ao seu governo, ele também pode indicar formas de organização das classes subalternas para a conquista da hegemonia". 
Podemos definir o PROFEPT como um exemplo deste espaço contra hegemônico, ou seja, o Estado, enquanto um aparelho, um instrumento, utiliza seus espaços institucionais para reproduzir a hegemonia do capital, mas, sem romantizar ou idealizar, este espaço contraditório comporta, também, a resistência organizada pelos professores. Deste modo, é o que Gramsci chama de "guerra de posição" ou "contra-hegemonia" em que "é preciso educar os trabalhadores para encorajar o surgimento de intelectuais dentro da classe trabalhadora, que defenderiam a transformação da sociedade capitalista através da revolução da classe trabalhadora". (NASCIMENTO, et al, 2008, p. 280)

E é esta a compreensão que temos da importância do PROFEPT visto que neste programa são formados os intelectuais que, espera-se, defenderão um outro projeto de sociedade baseado na defesa da articulação entre trabalho intelectual e trabalho manual.

\section{APONTAMENTOS FINAIS}

Considerando a importância atribuída pelo Estado e pela sociedade civil a Educação Profissional e Tecnológica no processo de reestruturação produtiva, é necessário sempre refletir algumas questões pertinentes - que tipo de educação está sendo ofertada nas escolas de EPT do país? Qual tipo de formação profissional espera-se nesta modalidade de ensino? Quais são os verdadeiros princípios e fundamentos da EPT? O que defendemos? Que tipo de professor esta modalidade requer? Quais os saberes docentes são requeridos a este profissional?

Estas são questões importantes e recorrentes no debate acerca da formação docente, em particular, para a EPT. O país precisa oportunizar espaços formativos que se coadunam com as transformações societais, mesmo que este espaço seja na educação formal e ofertada pelo sistema público de educação, como é o caso do PROFEPT.

Para além de uma visão maniqueísta compreende-se que as instituições superiores responsáveis pela formação inicial e continuada dos profissionais das diversas áreas do conhecimento são locais dialéticos de resistência e permanência, emancipação e manutenção, criticidade e alienação, justamente por que a realidade objetiva em que estas instituições estão inseridas é contraditória. Ressalta-se que "isso não significa dizer que a educação mudaria a sociedade, mas que a implementação da proposta gramsciniana de escola está dialeticamente ligada à extinção do modelo de escola atual". (NASCIMENTO, et al, 2008, p. 289)

A proposta educacional defendida pelo PROFEPT de base marxiana e gramsciana sustenta que a escola da EPT precisa: acompanhar as transformações do mundo do trabalho, compreender a indissociabilidade entre formação escolar e processo produtivo; defender que a formação humana seja integral e politécnica; que os docentes que atuam ou atuarão na EPT precisam ter uma formação que contemple as especificidades da EPT; 
que os profissionais da educação que atuam ou atuarão na EPT tenham um projeto educacional revolucionário e, acima de tudo, das necessidades formativas do trabalhador.

\section{REFERÊNCIAS}

ALTHUSSER. L. Aparelhos ideológicos do Estado. Notas sobre os aparelhos ideológicos do Estado (AIE). 2. ed. Rio de Janeiro. Edições Graal, 1985.

ANTUNES, Ricardo. Os sentidos do trabalho: ensaio sobre a afirmação e a negação do trabalho. São Paulo: Boitempo, 2000.

BRASIL. Lei $\mathbf{n}^{\circ}$ 11.892/2008. Brasília: Presidência da República, 2008.

Disponível em: http://www.planalto.gov.br/ccivil 03/ Ato2007-2010/2008/Lei/ L11892.htm. Acesso em: 18/06/2020.

BRASIL. Resolução do Conselho Superior n 161/2016. Espírito Santo: IFES, 2016. Disponível em: https://profept.ifes.edu.br/images/stories/ProfEPT/ Turma2017/Documentos/Res_CS_161_2016_-Cria_o_Programa_de_P \%C3\%B3s-gradua\%C3\%A7\%C3\%A3o_em_Educa

$\%$ C3\%A7\%C3\%A3o_Profissional_e_Tecnol

\%C3\%B3gica_e_aprova_seu_Regulamento_interno.pdf.pdf. Acesso em: 20/05/2020.

BRASIL. Lei n 9.394/1996. Brasília: Senado Federal, Coordenação de Edições Técnicas, 2017. Disponível em: https://www2.senado.leg.br/bdsf/ bitstream/handle/id/529732/lei_de_diretrizes_e_bases_1ed.pdf. Acesso em: 20/05/2020.

BRASIL. Regulamento do PROFEPT. Espirito Santo: IFES, 2018. Disponível em: https://profept.ifes.edu.br/images/stories/ProfEPT/Turma_2018/

Regulamento/Res_CS_22_2018_-_Regulamento.pdf. Acesso em: 20/05/2020.

BRASIL. Plataforma Nilo Peçanha. Brasília: SETEC/MEC, 2019. Disponível em: http://plataformanilopecanha.mec.gov.br/. Acesso em: 20/05/2020.

BRASIL. Programa de Pós-graduação em Educação Profissional e Tecnológica/PROFEPT. Espírito Santo: IFES, 2020. Disponível em: https:// profept.ifes.edu.br/doc. Acesso em: 20/05/2020.

CARVALHO, Olgamir Francisco de; SOUZA, Francisco Heitor de Magalhães. Formação do docente da educação profissional e tecnológica no Brasil: um diálogo com as faculdades de educação e o curso de Pedagogia. Revista Educação e Sociedade. Campinas, v. 35, n. 128, 2014. Disponível em: http://www.scielo.br/scielo.php?

script=sci_arttext\&pid=S0101-73302014000300883\&lng=en\&nrm=iso. Acesso em 16/06/2020.

COSTA, Elen de Fátima Lago Barros. Trabalho e carreira docente nos Institutos Federais de Educação, Ciência e Tecnologia. 2016. (Tese de 
Doutorado no Programa de Pós-graduação em Educação/UFSCar). São Carlos/SP: UFSCar, 2016. 265 p. Disponível em: Acesso em:

FRIGOTTO, Gaudêncio. Fundamentos científicos e técnicos da relação trabalho e educação no Brasil de hoje. In: LIMA, Júlio César França; NEVES, Lúcia Maria Wanderley (Orgs.). Fundamentos da educação escolar do Brasil contemporâneo. Rio de Janeiro: Editora FIOCRUZ, 2006, pp. 241-288.

FRIGOTTO, Gaudêncio. A Relação da Educação Profissional e Tecnológica com a Universalização da Educação Básica. Revista Educação \&

Sociedade, Campinas, vol. 28, n. 100 - Especial, 2007. Disponível em: https://www.scielo.br/pdf/es/v28n100/a2328100.pdf. Acesso em: 06/10/2015.

GRAMSCI, A. Cadernos do cárcere. Os intelectuais. O princípio educativo. Jornalismo. Volume 2, Rio de Janeiro: Civilização Brasileira, 2001.

GRAMSCI, A. Os intelectuais e a organização da cultura. Tradução de Carlos Nelson Coutinho. $8^{a}$ edição. Rio de Janeiro-RJ: Civilização Brasileira, 1991.

KUENZER, Acácia Z. As políticas de formação: a constituição da identidade do professor sobrante. Revista Educação \& Sociedade. Campinas/SP:

CEDES, n. 68, 1999. Disponível em: < http://www.plataformademocratica.org/ Publicacoes/17019_Cached.pdf>. Acesso em: 06/10/2015.

LIBANEO, José Carlos; PIMENTA, Selma Garrido. Formação de profissionais da educação: visão crítica e perspectiva de mudança. Revista

Educação\&Sociedade. Campinas, v. 20, n. 68, 1999. Disponível em: http://www.scielo.br/scielo.php?

script=sci_arttext\&pid=S0101-73301999000300013\&lng=en\&nrm=iso. Acesso em 20/05/2000.

MACHADO, Lucília R.S. Diferenciais inovadores na formação de professores para a educação profissional. Revista Brasileira da Educação Profissional e Tecnológica, Rio Grande do Norte, v. 1, n 1, 2008. Disponível em: http:// www2.ifrn.edu.br/ojs/index.php/RBEPT/article/view/2862. Acesso em 20/05/2000.

MACHADO, Lucília R. S. A politecnia nos debates pedagógicos soviéticos das décadas de 20 e 30 . Revista Brasileira da Educação Profissional e Tecnológica, Rio Grande do Norte, v. 1, n 18, 2020. Disponível em: http:// www2.ifrn.edu.br/ojs/index.php/RBEPT/article/view/9575. Acesso em 20/05/2000.

MOURA, Dante Henrique. Trabalho e formação docente na educação profissional. Curitiba: Instituto Federal do Paraná, 2014. Coleção formação pedagógica; v. 3. Disponível em: < https://curitiba.ifpr.edu.br/wp-content/ uploads/2016/05/Trabalho-e-Forma\%C3\%A7\%C3\%A3o-Docente.pdf>. Acesso em: 26/08/2017.

NASCIMENTO, Maria Isabel M. et al. A escola unitária: educação e trabalho em Gramsci. Revista HISTEBR online, Campinas, n.30, p.275-291, jun.2008. 
Disponível em: https://www.fe.unicamp.br/pf-fe/publicacao/5157/art17 30.pdf. Acesso em 20/05/2000.

SAVIANI, D. Trabalho e educação: fundamentos ontológicos e históricos. Revista Brasileira de Educação v. 12 n. 34 jan./abr. 2007. Disponível em: https://www.scielo.br/pdf/rbedu/v12n34/a12v1234.pdf. Acesso em: 26/08/2017.

SAVIANI, D. Pedagogia Histórico-crítica: primeiras aproximações. 7. ed. Campinas, SP: Autores Associados, 2000. 